\title{
Pemanfaatan bahan baku lokal dalam pengembangan wisata Pulau Cinta di Desa Teluk Kenidai Kecamatan Tambang Kabupaten Kampar Provinsi Riau
}

\author{
Trisla Warningsih*, Kusai, Lamun Bathara, Andarini Diharmi, \& Deviasari
}

Universitas Riau

* trisla.t.warningsih@lecturer.unri.ac.id

\begin{abstract}
Abstrak. Desa Teluk Kenidai terletak di Kecamatan Tambang Kabupaten Kampar Provinsi Riau. Desa Teluk Kenidai memiliki potensi wisata alam berupa pantai, yang menjadi salah satu destinasi wisata alternatif bagi masyarakat. Aktifitas yang dilakukan adalah bermain berbagai macam wahana dan berenang-renang di tepian Sungai Kampar. Pengunjung wisata pulau cinta di Teluk Kenidai merupakan pengunjung terbanyak dari seluruh objek wisata yang ada di Kabupaten Kampar. Keberadaan wisata pulau cinta dapat mengembangkan perekonomian masyarakat dengan menyediakan makanan khas sebagai oleh-oleh dan minuman untuk pengunjung wisata. Alternatif makanan yang dapat dilakukan adalah olahan ikan pantau crispy dan minuman sirup limau berhubung kedua hal tersebut memiliki potensi yang sangat tinggi di Kabupaten Kampar, serta dapat memberi nilai tambah bagi kehidupan masyarakat. Tujuan kegiatan untuk memberdayakan masyarakat Desa Teluk Kenidai, untuk melakukan pengolahan ikan pantau crispy yang variatif serta dapat meningkatkan daya tarik pulau cinta bagi wisatawan yang berkunjung. Manfaat kegiatan yaitu membuka wawasan masyarakat dalam meningkatkan potensi sumber daya alam, memperoleh keterampilan dan kemampuan dalam pembuatan ikan pantau crispy dan sirup limau untuk meningkatkan ekonomi. Metode dilakukan dengan demonstrasi dan praktek langsung dalam pembuatan ikan pantau crispy dan sirup limau. Masyarakat sasaran adalah masyarakat yang tinggal di Desa Teluk Kenidai dan pemangku adat desa serta Kelompok Sadar Wisata (Pokdarwis) yang berjumlah 15 orang. Evaluasi dilakukan dengan memberikan kuesioner pada seluruh peserta sebelum dan setelah penyampaian materi penyuluhan dan praktek yang dilakukan. Hasil evaluasi dari kegiatan pengabdian yang telah dilakukan menunjukkan bahwa meningkatnya keinginan masyarakat dalam mempraktekkan kegiatan penyuluhan untuk memperoleh penghasilan tambahan dengan membuka usaha ini khususnya di kawasan wisata pulau cinta di Desa Teluk Kenidai.
\end{abstract}

Kata kunci: Teluk Kenidai, wisata pulau cinta, nilai tambah

Abstract. Teluk Kenidai Village is located in Tambang District, Kampar Regency, Riau Province. Teluk Kenidai Village has the potential for natural tourism in the form of beaches, which are one of the alternative tourist destinations for the community. The activities carried out are playing various kinds of rides and swimming on the banks of the Kampar River. The visitors to the island of love in Kenidai Bay are the largest visitors of all tourist objects in Kampar Regency. The existence of the island of love tourism can develop the community's economy by providing special foods as souvenirs and drinks for tourist visitors. Alternative foods that can be done are processed crispy monitor fish and lime syrup drinks because these two things have very high potential in Kampar Regency, and can provide added value to people's lives. The purpose of the activity is to empower the people of Teluk Kenidai Village, to process various crispy monitoring fish and to increase the attractiveness of the island of love for visiting tourists. The benefits of the activity are opening up people's insights in increasing the potential of natural resources, gaining skills and abilities in making crispy monitor fish and lime syrup to improve the economy. The method is carried out by demonstration and hands-on practice in the manufacture of crispy monitoring fish and lime syrup. The target communities are the people living in Teluk Kenidai Village and village customary leaders and the Tourism Awareness Group (Pokdarwis) totaling 15 people. Evaluation is carried out by giving questionnaires to all participats before and after the delivery of counseling materials and practices. The results of the evaluation of the community service activities that have been carried out show that the increasing desire of the community in practicing extension activities to earn additional income by opening this bussines, especially in the tourist area of Pulau Cinta in Teluk Kenidai Village.

Keywords: Teluk Kenidai, pulau cinta tour, value-added 
To cite this article: Warningsih, T., Kusai., L. Bathara., A. Diharmi., \& Deviasari. 2020. Pemanfaatan bahan baku lokal dalam pengembangan wisata Pulau Cinta di Desa Teluk Kenidai, Kecamatan Tambang, Kabupaten Kampar Provinsi Riau. Unri Conference Series: Community Engagement 2: 38-43. https://doi.org/10.31258/unricsce.2.38-43

Peer-review under responsibility of the organizing committee of Seminar Nasional Pemberdayaan Masyarakat 2020

\section{PENDAHULUAN}

Pariwisata merupakan kesatuan dari beberapa elemen seperti wisatawan, daerah tujuan wisata, perjalanan, industri dan lain sebagainya yang merupakan kegiatan pariwisata. Indonesia memiliki beraneka ragam jenis pariwisata seperti wisata alam, sosial maupun wisata budaya yang menjadi sumber devisa negara (Devy \& Soemanto, 2017). Wisata alam merupakan bentuk kegiatan wisata yang memanfaatkan potensi sumberdaya alam dan tata lingkungan yang meliputi objek dan kegiatan yang berkaitan dengan rekreasi dan pariwisata yang memanfaatkan potensi sumberdaya alam dan ekosistemnya, baik dalam bentuk asli (alami) maupun perpanduan dengan buatan manusia (Sowantoro, 2002)

Desa Teluk Kenidai memiliki potensi wisata alam berupa pantai, yang menjadi salah satu destinasi wisata alternatif bagi masyarakat. Aktifitas yang dilakukan adalah bermain berbagai macam wahana dan berenangrenang di tepian Sungai Kampar. Di antara lintasan pantai, terbentang kawasan hutan seluas 5 ha, yang memiliki suasana natural dan terdapat beberapa jenis tumbuhan didalamnya. Ada juga Taman Bunga Cinta yang ditumbuhi Eceng Gondok seluas 30 x $100 \mathrm{~m}$. Tempat ini sangat indah jika dijadikan latar belakang berswafoto atau foto bersama. Pengunjung dapat menikmati berbagai jenis makanan dan minuman dengan harga yang sangat terjangkau. (Dinas Pariwasata Kabupaten Kampar, 2018) menyatakan bahwa pengunjung sebanyak 300.695 pelajar/mahasiswa, 402.099 wisatawan nusantara dan 69 wisatawan mancanegara sejak Januari hingga Agustus 2018. Pengunjung wisata Pulau Cinta di Teluk Kenidai merupakan pengunjung terbanyak dari seluruh objek wisata yang ada di Kabupaten Kampar. Ini berarti bahwa ada banyak pengunjung yang tertarik dengan tempat ini ditambah lagi wisata pulau cinta tersebut terletak $12 \mathrm{~km}$ dari Bandara Internasional Sultan Syarif Kasim II kota Pekanbaru dengan lama perjalanan hanya 25 menit yang menambah daya tarik wisatawan untuk berkunjung ke tempat wisata ini. Tempat wisata pulau cinta ini telah dikelola dengan baik oleh Kelompok Sadar Wisata (Pokdarwis) Kabupaten Kampar.

Keberadaan Kegiatan wisata pulau cinta ini akan mempengaruhi keadaan masyarakat Teluk Kenidai sehingga meningkatkan perekonomian sektor informal melalui penyediaan makanan dan wahana berbagai jenis permainan untuk wisatawan yang berkunjung. Dalam hal ini, penyedia makanan yang dapat dikembangkan di kawasan Pulau Cinta sebagai makanan cepat saji berupa ikan pantau crispy, sedangkan untuk minumannya berupa sirup limau dikarenakan potensi perikanan serta banyaknya produksi limau di Kabupaten Kampar,. Dari berbagai potensi tersebut, maka melalui pengabdian kepada masyarakat di Desa Teluk Kenidai ini diharapkan dapat lebih meningkatkan semangat masyarakat dalam mengembangkan wisata Pulau Cinta ini untuk semakin dikenal didalam dan diluar negeri.

\section{METODE PENERAPAN}

\section{Sosialisasi}

Tahap awal pelaksanaan ini adalah sosialisasi program. Setelah tim menemukan potensi-potensi yang dapat dikembangkan seperti potensi wisata pulau cinta di Desa Teluk Kenidai melalui berbagai teknologi tepat guna. Dalam hal ini Desa Teluk Jering memiliki sumber daya alam yang menarik dan melimpah baik sumber daya perkebunan, pertanian, serta kehutanan.

Pengembangan dan pengelolaan potensi wisata pulau cinta Teluk Kenidai dilakukan dengan mensurvei yang kemudian akan dipetakan menjadi berbagai media interaktif agar dapat berguna dan lebih dapat dipahami masyarakat luas. Adapun potensi yang ada juga kemudian diolah menjadi lebih bermanfaat dan memberi nilai tambah bagi kehidupan masyarakat. Luaran dari Pengembangan dan Pengelolaan ini berupa: Peningkatan Promosi Objek Wisata Alam Pulau Cinta, pembuatan spanduk Peta Wisata Pulau Cinta, pembangunan pelayanan publik di bidang Kebersihan dan Promosi Wisata serta peningkatan daya tarik Pulau Cinta bagi wisatawan lokal. 


\section{Peningkatan Pemahaman dan Pemberdayaan Masyarakat}

Langkah selanjutnya adalah menjumpai tim usaha yang dikelola oleh masyarakat setempat, terutama kelompok sadar wisata (Pokdarwis) yang berada di Desa Teluk Jering maupun beserta tokoh masyarakat yang akan mempermudah dalam peningkatan pemahaman dan pemberdayaan masyarakat. Dengan adanya pengabdian kepada masyarakat ini, diharapkan masyarakat Desa Teluk Kenidai paham akan kebersihan, keindahan dan keramahtamahan terhadap wisatawan. Maka dari itu beberapa program akan berupa Sosialiasi Sadar Wisata di beberapa aspek, seperti : Peningkatan pemahaman pasyarakat terhadap potensi wisata yang dimiliki desa Teluk Kenidai, peningkatan pemahaman masyarakat bidang kepariwisataan akan pentingnya potensi yang dimiliki objek wisata pulau cinta yang sudah menjadi icon pariwisata bagi masyarakat setempat. Kegiatan pemberdayaan ini memiliki luaran berupa, peningkatan pelayanan publik berupa fasilitas umum dan promosi wisata pulau cinta di Desa Teluk Kenidai.

\section{Pembuatan Media Promosi}

Langkah selanjutnya setelah bertemu tim pokdarwis adalah mengadakan penyuluhan maupun pelatihan untuk meningkatkan kompetensi sumber daya manusia dalam meningkatkan pembuatan media promosi, selain menawarkan keindahan lokasi dan pelayanan publik tersebut, juga harus memberikan edukasi kepada pemirsa agar masyarakat juga dapat terinspirasi untuk menjaga kelestarian lingkungan sekitarnya promosi wisata pulau cinta di Desa Teluk Kenidai. Pengadaan fasilitas penunjang pun akan direalisasikan seperti pengadaan sarana dan prasarana yang dibutuhkan untuk menunjang kegiatan.

\section{Promosi dan kerjasama lain}

Tahap selanjutnya merupakan tahap promosi yang mana tahap promosi ini akan berperan penting dalam pemasaran potensi wisata dengan menggunakan metode pelaksanaan dan dokumentasi berdasarkan hasil lapangan yang sudah dilakukan. Selain membuat video promosi, keluaran yang lain adalah berupa website, facebook dan instagram yang akan terus memberikan update mengenai perkembangan wisata pulau cinta Teluk Kenidai di kecamatan Tambang Kabupaten Kampar.

\section{Pendampingan dan evaluasi}

Tahap terahkir merupakan tahap pendampingan dan evaluasi. Program pendampingan sendiri berupa pendampingan langsung ke lapangan maupun pendampingan melalui perantara (media). Pendampingan berupa pengelolaan destinasi wisata Teluk Jering untuk menambah wisata baru. Kemudian tahap evaluasi, tahap ini merupakan tahap dimana program akan dievaluasi secara menyeluruh untuk meningkatkan daya tarik dalam pengembangan perekonomian masyarakat selanjutnya.

\section{Monitoring}

Monitoring akan dilaksanakan pada bulan berikutnya, di mana tim UNRI akan berkunjung kembali untuk melihat kondisi di lapangan, apakah masyarakat sasaran telah menerapkan hasil pengabdian. Selain monitoring, tim UNRI juga melakukan evaluasi dan melayani Tanya jawab apabia ada hal-hal yang ingin diketahui oleh masyarakat sasaran penyuluhan.

\section{HASIL DAN KETERCAPAIAN SASARAN}

\section{Pertemuan dan Penyerahan Alat}

Pertemuan dan penyerahan alat (Gambar 1) dilakukan pada 22 Juli 2020 antara anggota Pokdarwis Pulau Cinta di Desa Teluk Kenidai dengan Tim Pengabdian Masyarakat FPK Universitas Riau. Pertemuan ini bertujuan untuk memberdayakan masyarakat di kawasan wisata Pulau Cinta Desa Teluk Kenidai, Kampar agar dapat mengolah hasil perikanan menjadi olahan yang variatif dan siap saji.

Berdasarkan pertemuan ini diketahui bahwa sebagian besar masyarakat tidak mengetahui produk olahan ikan pantau crispy. Berhubung di kawasan wisata Pulau Cinta banyak dijumpai ikan Salansek sehingga besar antusias masyarakat dalam mengikuti kegiatan ini untuk belajar serta mencari uang. 

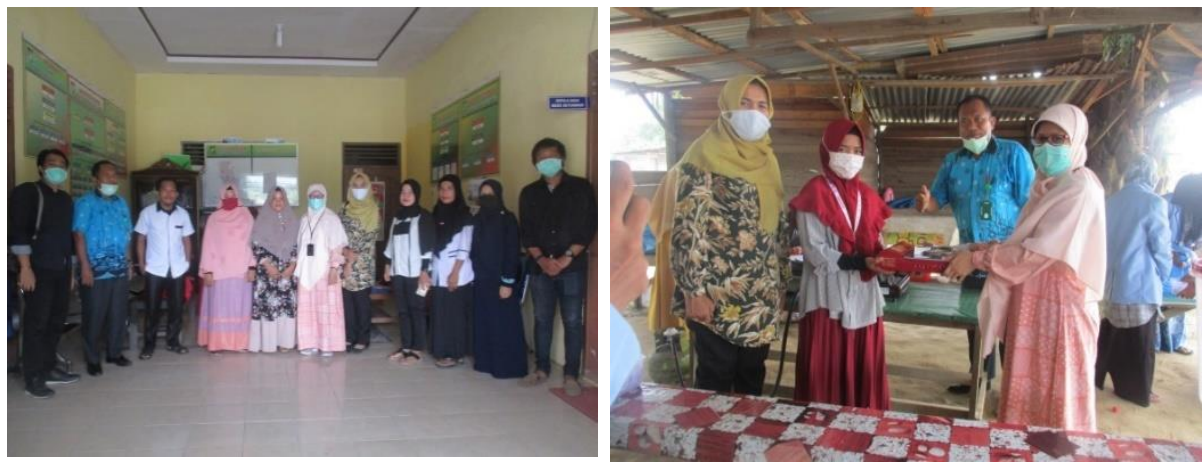

Gambar 1 Pertemuan dan penyerahan Alat oleh Tim Pengabdian FPK Universitas Riau kepada anggota Pokdarwis Pulau Cinta

\section{Penyampaian Materi}

Penyampaian materi dilakukan di sekitar kawasan pulau cinta di Desa Teluk Kenidai (Gambar 2) penyajian materi diawali oleh MC dari mahasiswa KKN Desa Teluk Kenidai, kemudian penyampaian materi oleh ketua Tim Pengabdian FPK Universitas Riau Dr. Trisla Warningsih, S.Pi, M.Si. Kegiatan ini melibatkan secara aktif mahasiswa kukerta Universitas Riau 2020. Sebelum penyampaian materi, masyarakat selaku peserta dibagikan deskripsi bahan ajar untuk memudahkan dalam memahami materi yang akan disampaikan. Materi berupa :

1. Penjelasan mengenai potensi perikanan serta produksi limau di Kabupaten Kampar

2. Kandungan gizi pada ikan

3. Prosedur pembuatan ikan pantau crispy

4. Bahan, cara pengemasan dan pemberian lebel pada produk

5. Strategi pemasaran produk olahan

6. Sosialisasi berwisata ditengah pandemi dengan tetap mematuhi protokoler kesehatan
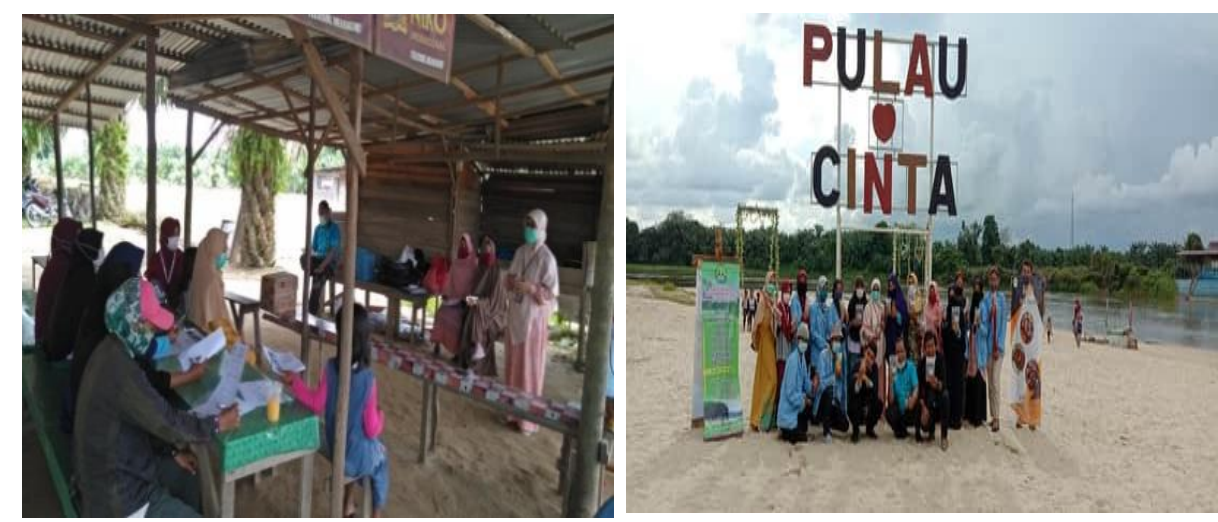

Gambar 2. Penyampaian materi tim pengabdian FPK Universitas Riau

Selama penyampaian materi peserta juga dipersilahkan untuk mengajukan pertanyaan terhadap materi yang kurang dipahami. Diskusi berjalan dengan baik, bahkan sebagian besar peserta antusias untuk mengikuti prakteknya secara langsung.

\section{Praktek Pembuatan Ikan Pantau Crispy dan Sirup Limau}

a. Pembuatan Ikan Pantau Crispy

Praktek pembuatan ikan pantau crispy, pertama siapkan bahan-bahan seperti ikan pantau, bersihkan ikannya terlebih dahulu dan diberi sedikit perasan jeruk nipis agar ikan tidak amis. Kemudian untuk $1 \mathrm{~kg}$ ikan adonan basahnya tepung terigu $15 \mathrm{sdm}$, tepung beras $5 \mathrm{sdm}$, garam $2 \mathrm{sdt}, 2 \mathrm{sdt}$ merica/lada bubuk, 2 sdt ketumbar, sedikit daun jeruk dan air secukupnya dicampurkan serta aduk-aduk, kemudian bikin adonan keringnya dengan menambahkan tepung terigu secukupnya, lalu diberi sedikit garam, masukkan adonan basahnya dan adukaduk, goreng ikan pada api sedang dengan minyak panas hingga ikan tenggelam, setelah warna ikan berubah 
menjadi coklat keemasan, angkat lalu tiriskan, Setelah dingin masukkan ke dalam kemasan yang telah diberi label.
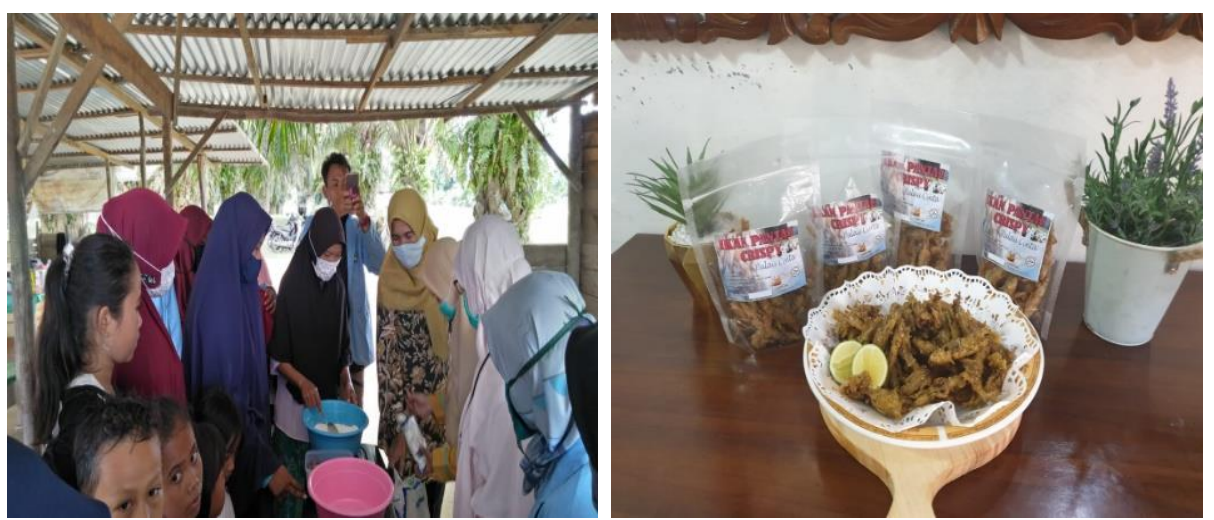

Gambar 3. Pembuatan Ikan Pantau Crispy

\section{b. Pembuatan Sirup Limau}

Praktek pembuatan sirup limau bersama masyarakat dengan cuci bersih jeruk peras, belah menjadi dua dan peras airnya. Masukkan peras jeruk kedalam panci dan nyalakan api, untuk $1 \mathrm{~kg}$ jeruk dihasilkan kurang lebih 600-700 ml sari jeruk. Tambahkan $200 \mathrm{ml}$ air ke dalam sari jeruk, masukkan gula pasir, sesuaikan dengan selera saja. Aduk-aduk terus selama pemanasan agar gula tidak hangus dan membuat tampilan sirup menjadi jelek, setelah gula larut, aduk terus sampai sirup mendidih, matikan api, tunggu dingin lalu saring sirup dengan menggunakan kain halus agar sirup yang dihasilkan bersih dan bening. Sirup jeruk perasnya sudah jadi, masukkan ke wadah dan simpan di dalam kulkas supaya lebih awet.
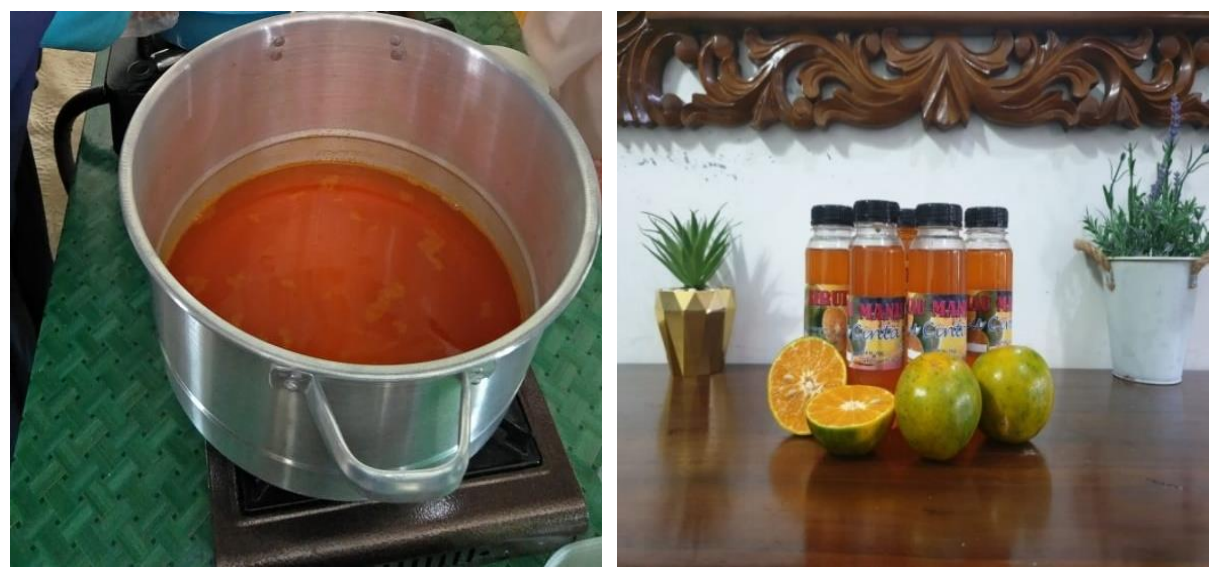

Gambar 4. Pembuatan sirup limau

\section{KESIMPULAN}

Ketertarikan masyarakat dalam pembuatan ikan pantau crispy dan sirup limau sangat besar. Setelah penyampaian materi oleh tim pengabdian mengenai potensi perikanan serta banyaknya produksi limau di Kabupaten Kampar, menambah semangat masyarakat untuk melakukannya sendiri serta dari hasil pengabdian ini keinginan masyarakat untuk menambah penghasilan dengan membuka usaha ini sangat tinggi khususnya di kawasan wisata pulau cinta di Desa Teluk Kenidai Kecamatan Tambang Kabupaten Kampar. 


\section{UCAPAN TERIMA KASIH}

Terimakasih kami ucapkan kepada Lembaga Penelitian dan Pengabdian Masyarakat (LPPM) Universitas Riau telah memberi dana pengabdian kepada tim pengabdian FPK Universitas Riau tahun 2020. Penulis juga mengucapkan terimakasih kepada Kepala Desa Teluk Kenidai, Kelompok Sadar Wisata (Pokdarwis) Pulau Cinta dan mahasiswa kukerta UNRI yang telah berkontribusi besar dalam pelaksanaan kegiatan ini.

\section{DAFTAR PUSTAKA}

Devy, H. A., \& Soemanto, R. B. (2017). Pengembangan Obyek Dan Daya Tarik Wisata Alam Sebagai Daerah Tujuan Wisata di Kabupaten Karanganyar (Studi Kasus Obyek Wisata Air Terjun Jumog di Kawasan Wisata Desa Berjo, Kecamatan Ngargoyoso, Kabupaten Karanganyar). Jurnal Sosiologi DILEMA, 32(1).

Dinas Pariwasata Kabupaten Kampar. (2018).

Https://Pekanbaru.tribunnews.com/2018/10/28/pulau-cinta-teluk-jering-primadina-baru-wisata-riau?page=4

Sowantoro, G. (2002). Casar-Dasar Pariwisata, Upaya Pengembangan Pariwisata Alternatif. Yogyakarta: Andhi. 